\title{
Comparative Analysis of the Effectiveness of the Action of a Scorer From a NBA Team and One of the Basketball National League
}

\author{
Onose lonuț ${ }^{1 *}$ \\ Hodorcă Raluca Mihaela ${ }^{2}$ \\ Petrea Renato Gabriel ${ }^{3}$ \\ Soveja Andrei ${ }^{4}$ \\ 1,2,3,4 “Al.I.Cuza” University Iași, Bulevardul Carol I, 700506, Romania
}

Keywords: basket, efficiency, Golden States Warriors, CSM Oradea

\begin{abstract}
The complexity and diversity of the game of basketball are the basic elements that define it as a sport, being watched and practiced by a significant number of people. Professional League attract the best practitioners of basketball from all corners of the world. In Romania, basketball becomes the forefront of sports games through consistency of import of foreign players alongside domestic ones, create attractive moments for the present spectators. In the conduct of the study, it has gone from the suppisition that there are significant differences between the effectiveness of action by the scorer from a team in the NBA and one in the LNB. Research has been carried out during the regular season, 2015-2016, 2 teams being analysed are representative of their respective Championships: Golden States Warriors and CSM Oradea. As a result of carrying out the analysis, the surprising results that concluded certain aspects of effectiveness in the teams.
\end{abstract}

\section{Introduction}

Being the game, who wins, among young people, a high level of popularity, basketball is characterized by smoothness, precision and technical exercises and tactical fantasy through waist high and physical qualities of the athletes, all of them involved in a combat sport that claims the team spirit and sacrifice.

Basketball practice in Romania has become a refreshing and simple method of leisure, children being seen increasingly more often on the basketball court. From the point of view of marketing, recent years have meant a recovery and an outcome of the basketball phenomenon from Romania.

National Basketball League (LNB) proposes interesting games, teams in the National Championships to create a unique sporting spectacle. Through the use of increasingly frequent foreign players attempting to optimise and professionalise the game, wishing is raising motor performance, with a view to gearing and teams in

\footnotetext{
*E-mail: onoseionut@yahoo.com;
} 
international competitions. At the same time, despite the huge differences in salary, more players who have enabled the NBA to play in Europe (Edelman, 2010).

The National Basketball Association (NBA) is basketball's elite. The best players are included in the quoted 30 teams divided into two conferences: Eastern Conference and Western Conference.

With remarkable skills, driving qualities shine, NBA games, he created the show for any lover of the sport. With substantial salaries (Lebron, according to ESPN has 2016-2017 season salary of US \$30,963,450.), the top players leading up the game of basketball to a true marketing and management industry.

\section{Material and methods}

The idea has gone into the design and analysis of the work, is the ease with which professional players to bring results from action, throws the whole process of being placed on the basis of any successful training and complex, as well as the particularities of the players.

Using a more accurate analysis of the results obtained using the method of observation (Epuran, 2005), we wish to highlight the preffered factors for sports performance.

Hypothese. The supposition of the study is that there are significant differences between the percentages of success a scorer from the action team in the NBA and one in the NBL.

Having different characteristics, in terms of the rules of the game are not the same, the study can be objectively in the light of the analysis of the percentage of enrollment from basket basketball games.

The teams have been analyzed in the professional football period 2015-2016, being pursued their developments during the entire season.

The duration of the game represents a first issue that requires. The NBL, according to the Regulation (URfrbaschet.ro), a match lasts for 40 minutes of the game. In the NBA, playing time is 48 minutes. For this reason, as well as game design, from the North American League professionals use a principle of turnover of players, from Romania. Average core gamers are used for 27,8 $( \pm 6.9)$ minutes, and reserve for $11.3( \pm 7.0)$ minutes of playing (Gonzalez et al., 2013).

The method of completion of actions represents another characteristic different from the NBA game. Thanks to the motor qualities, professional players use "up" as a frequent method of completion. In contrast, in Europe, usually only players receiving the ball in the Center "post" in order to complete the action (Mavridis, 2009). True athletes, another easy method of completion of the operations is to counterattack. Increasing the intensity of the counterattack, NBA players are able to increase the percentage of successful and thus to approach the victories of matches (Courel, McRobert \& Cardenas, 2014).

Land size is different, both in terms of dimensions, but especially in the light of limited space for throwing 3 points (fig. 1). Players in Europe for 3-point throws with $0.5 \mathrm{~m}$ nearer than those in the NBA, being thus theoretically easier marking points away. 


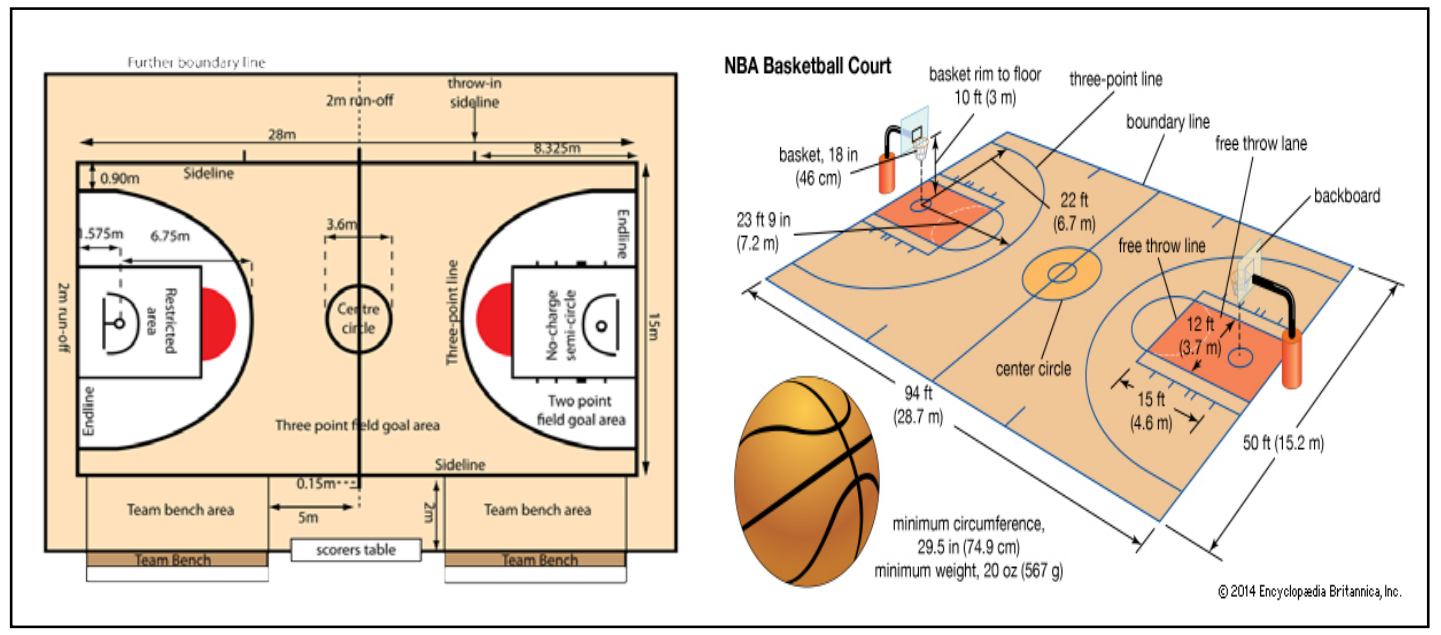

Figura 1. Standard dimensions of the land of basketball in the NBA, respectively NBL (Tutorialpoint, Pinterest)

In the context of the work were analyzed the success from action 2 teams that have won championships in the NBA 2015-2016 season and NBL respectively. These teams are CSM Oradea and the Golden States Warriors.

Overseas team consists of the following players (Table 1):

Table 1. Team Golden States Warriors, 2015-2016 season (Fox Sports Networks)

\begin{tabular}{lcc}
\hline Name & Height (cm) & Position \\
\hline Ezeli Festus & 211 & Center \\
Thompson Klay & 201 & Guard \\
Barnes Harrison & 203 & Forward \\
Green Draymond & 201 & Forward \\
Curry Stephen & 190 & Guard \\
Barbosa Leandro & 190 & Guard \\
Bogut Andrew & 213 & Center \\
Iguodala Andre & 198 & Forward \\
Livingston Shaun & 201 & Guard \\
Rush Brandon & 198 & Guard \\
Speights Marreese & 208 & Forward / Center \\
Clark Ian & 190 & Guard \\
Varejao Anderson & 211 & Center \\
McAdoo James-Michael & 206 & Forward \\
Looney Kevon & 206 & Center \\
\hline
\end{tabular}

In the 2015-2016 season, CSM Oradea team had featured on the following players: (Table 2) 
Table 2. CSM Oradea, team players 2015-2016 season (The Romanian Basketball Federation)

\begin{tabular}{lcc}
\hline Name & Height (cm) & Position \\
\hline Zeno Martin & 196 & Guard \\
Franklin William & 184 & Guard \\
Barnette Sean & 210 & Forward \\
Nuhanovici Salih & 210 & Center \\
Mandache Andrei & 191 & Guard / Forward \\
Lucic Uros & 207 & Forward \\
Markovic Radovan & 193 & Guard \\
Barac Nemanja & 194 & Guard \\
Zupan Miha & 205 & Forward / Center \\
Lupusavei Silviu & 182 & Guard \\
Pașca Rareș & 198 & Forward \\
Niculescu Bogdan & 199 & Forward \\
Țibârnă Bogdan & 210 & Center \\
Petrișor Cătălin & 184 & Guard \\
\hline
\end{tabular}

The two teams have played a different number of games against opponents (Table 3), in the framework of these matches each team was analyzed in order to benefit the offensive, quantification of results.

Table 3. The evolution of research teams that are in season 2015-2016

\begin{tabular}{lccc}
\hline Team & Total no. of games & Wins & Defeats \\
\hline CSM Oradea & 32 & 23 & 9 \\
Golden State Warriors & 82 & 73 & 9 \\
\hline
\end{tabular}

\section{Results and Discussions}

In this study were compared for rolls from a total of 114 games, the results being relevant to the elaboration of the conclusions. Thus, the situation for the basketball team the Golden States Warriors is given in Table 4.

Romanian Team champion CSM Oradea presents the following statistical values for the 2015-2016 season in Table 5. 
Table 4. Statistics for the Golden States Warriors, 2015-2016 season

(Sports Reference)

\begin{tabular}{lccccc}
\hline Name & Games & Points / Game & Throws / Game & 2 points \% & 3 points \% \\
\hline Stephen Curry & 79 & 30.1 & 10.2 & $50.4 \%$ & $45.4 \%$ \\
Klay Thompson & 80 & 22.1 & 8.1 & $47 \%$ & $42.5 \%$ \\
Draymond Green & 81 & 14 & 5 & $49 \%$ & $38.8 \%$ \\
Harrison Barnes & 66 & 11.7 & 4.5 & $46.6 \%$ & $38.3 \%$ \\
Andre Iguodala & 65 & 7 & 2.7 & $47.8 \%$ & $35.1 \%$ \\
Marrese Speights & 72 & 7.1 & 2.7 & $43.2 \%$ & $38.7 \%$ \\
Festus Ezeli & 46 & 7 & 2.7 & $54.8 \%$ & $0.0 \%$ \\
Shaun Livingston & 78 & 6.3 & 2.6 & $53.6 \%$ & $16.7 \%$ \\
Leandro Barbosa & 68 & 6.4 & 2.5 & $46.2 \%$ & $35.5 \%$ \\
Andrew Bogut & 70 & 5.4 & 2.5 & $62.7 \%$ & $100.0 \%$ \\
Brandon Rush & 72 & 4.2 & 1.5 & $42.7 \%$ & $41.4 \%$ \\
Ian Clark & 66 & 3.6 & 1.3 & $44.1 \%$ & $35.7 \%$ \\
James Michael McAdoo & 41 & 2.9 & 1.1 & $53.6 \%$ & $50.0 \%$ \\
Andreson Varejao & 53 & 2.6 & 1 & $42.7 \%$ & $0.0 \%$ \\
\hline
\end{tabular}

Table 5. Statistics for CSM Oradea, 2015-2016

(The Romanian Basketball Federation)

\begin{tabular}{lccccc}
\hline Name & Games & Points / Game & Throws / Game & 2 points \% & 3 points \% \\
\hline Daniel Popescu & 13 & 2.2 & 0.5 & $33.3 \%$ & $42.1 \%$ \\
William Franklin & 22 & 9.5 & 4.3 & $48.9 \%$ & $36.4 \%$ \\
Bogdan Niculescu & 14 & 0.9 & 0.4 & $50.0 \%$ & $25.0 \%$ \\
Nemanja Barac & 17 & 7.4 & 4.4 & $56.0 \%$ & $15.0 \%$ \\
Miha Zupan & 8 & 10.5 & 3.6 & $55.0 \%$ & $43.8 \%$ \\
Catalin Petrisor & 7 & 0.7 & 0.6 & $25.0 \%$ & $0.0 \%$ \\
Radovan Markovic & 22 & 13.7 & 3.2 & $60.0 \%$ & $43.3 \%$ \\
Rares Pasca & 22 & 2.5 & 1 & $45.0 \%$ & $32.0 \%$ \\
Bogdan Tibarna & 10 & 7.5 & 3.7 & $64.9 \%$ & $40.0 \%$ \\
Salih Nuhalovic & 21 & 8.8 & 6.5 & $53.7 \%$ & $0.0 \%$ \\
Silviu Lupusavei & 1 & 0 & 0 & $0.0 \%$ & $0.0 \%$ \\
Sean Barnette & 21 & 12.9 & 8.2 & $49.7 \%$ & $43.6 \%$ \\
Uros Lucic & 21 & 10.3 & 6.4 & $47.4 \%$ & $41.8 \%$ \\
Andrei Mandache & 22 & 8.5 & 3.3 & $58.3 \%$ & $32.1 \%$ \\
\hline
\end{tabular}

The ratio between the number of throws and submited by players of both teams, are presented in Table 6:

Table 6. Efficiency of the action the scorer from two teams analysed

\begin{tabular}{ccc}
\hline Team & 2 points \% & 3 points \% \\
\hline Golden State Warriors & $48.7 \%$ & $41.6 \%$ \\
CSM Oradea & $52.8 \%$ & $37.6 \%$ \\
\hline
\end{tabular}




\section{Discussions}

Analysing the results obtained, we may compile certain conclusions on the relationship between the percentage of success from action for the two teams that are in the study. If in the case of 2-point scorer, team CSM Oradea has a percentage higher than the NBA team, in the case of 3-point scorer, the situation reverses.

Multiple explanations may be compared with the existing level of play in the two Championships. The large number of successful team 3 points for the Golden States Warriors represents the new philosophy of the NBA. Teams prefer rolls away, setting new records of effectiveness (25 throws of 39 attempts in one game for the Cleveland Cavaliers, 3.03.2017).

If said team threw 39 times at 3-point basket, this represents an average of 10 sets/quarter, an extremely high value for the game of basketball. However, the difference between the successful 2-point scorer and 3-point is relatively low (48.7\% and $41.6 \%$ ), indicating the exceptional technical preparation of professional players who manage to achieve outstanding performance in the context of the aggressive defenses.

The NBL, although the distance from which is recorded throwing a 3 points is with $0.5 \mathrm{~m}$ lower than in the NBA, the scorer, is suffering from a serious imbalance in relation to the one at semidistance or close the Panel $(52.8 \%$ from $37.6 \%)$. Thus the method of preparation of a tactical game in which combinations are made in such a way as to benefit players throw from near the basket unchallenged. This situation highlights the features of the game of basketball in Romania, where the technique during a game can be improved.

\section{Conclusions}

Comparing the results of the teams, it can be said that there are significant differences between the percentage of success action of StateWarriors from Golden and CSM Oradea, confirming the proposed hypothesis. If the team from Romania has, surprisingly, a higher percentage of success than the U.S. at rolls of 2 points, 3 points for throws, Americans are superior.

The situation can be explained thus: the NBA players ' desire to produce the show and to the opportunity to gain a higher score than a possible adversary that would use mostly rolls of 2 points, the game overseas gains special meanings.

At the same time, the fact that the reserves are used for longer, than in Europe, makes the players more rest holders so as to not lose from the technical virtuosity.

Basketball matches to bring in an increasing number of spectators. Although it has different characteristics in terms of players, represents beauty and celebrated during a game should be admired, as a starting point for the promotion and encouragement of the practice of all storeys of the game of basketball. 


\section{References}

1. COUREL, J., MCROBERT, A.P., \& CARDENAS, D. (2014). The impact of match status on game rhythm in nba basketball, 19th annual Congress of the European College of Sport Science 2nd - 5th July 2014, Amsterdam;

2. EDELMAN, M. (2011). Does the NBA Still Have 'Market Power'? Exploring the Antitrust Implications of an Increasingly Global Market for Men's Basketball Player Labor, Rutgers Law Journal, 3(41): 549;

3. EPURAN, M. (2005). Metodologia cercetării activităților corporale, Bucuresti: FEST, 205;

4. GONZALEZ, A., HOFFMAN, J.R., ROGOWSKI, J.P., BURGOS, W., MANOLO, E., WEISE, K., FRAGALA, M.S. \& STOUT, J.R. (2013). Performance Changes in NBA Basketball Players Vary in Starters vs. Nonstarters Over a Competitive Season, Journal of Strength \& Conditioning Research, 3(27), 611-615;

5. MAVRIDIS, G. (2009). The inside game in World Basketball. Comparison between European and NBA teams, International Journal of Performance Analysis in Sport, 2(9), 157-164;

6. ENTERTAINMENT AND SPORTS PROGRAMMING NETWORKS. (1979). Retrieved in 2017 from: http://www.espn.com/nba/salaries

7. FOX SPORTS NETWORKS. (1996). Retrieved from http://www.foxsports.com/nba/golden-state-warriors-team roster?season $=2015$

8. PINTEREST (2010, March). Retrieved from https://www.pinterest.com/pin/499547783640409960/

9. SPORTS REFERENCE. (2004). Retrived from http://www.basketballreference.com/teams/GSW/2016.html

10. THE ROMANIAN BASKETBALL FEDERATION (2000). Retrieved from http://www.frbaschet.ro/documente/download/Regulamentul\%20Oficial\%20 al\%20Jocului\%20de\%20Baschet_F1.pdf

Retrieved from http://www.frbaschet.ro/echipe/liga-nationala-de-baschetmasculin/cs-municipal-oradea?season_id=92323\#mbt:17-200-team $01 \$ \mathrm{t} \& 0=4$

11. TUTORIALS POINT (2006). Retrieved from https://www.tutorialspoint.com/basketball/basketball_quick_guide.htm 


\title{
Analiza Comparativă a Eficienței Aruncărilor din Acțiune Dintre o Echipă ce Activează în NBA și Una din Liga Națională de Baschet
}

\author{
Onose lonuț ${ }^{1}$ \\ Hodorcă Raluca Mihaela ${ }^{2}$ \\ Petrea Renato Gabriel ${ }^{3}$ \\ Soveja Andrei ${ }^{4}$ \\ 1,2,3,4 Universitatea “Al.I.Cuza” din Iași, Bulevardul Carol I, 700506, Iaşi, România
}

Cuvinte cheie: baschet, coșuri marcate, eficiență, Golden State Warriors, CSM Oradea

\section{Rezumat}

Complexitatea și diversitatea jocului de baschet sunt elementele de bază care îl definesc ca disciplină sportivă, fiind urmărit și practicat de către un număr important de oameni. Liga profesionistă din SUA atrage cei mai buni practicanți de baschet din toate colțurile lumii. În România, baschetul revine în prim-planul jocurilor sportive prin consistența importului de jucători străini, care alături de cei autohtoni, crează momente atractive pentru spectatorii prezenți. În realizarea studiului, s-a plecat de la presupunerea că există diferențieri semnificative între eficiența aruncărilor din acțiune la o echipă din NBA şi una care activează în LNB. Cercetarea s-a desfășurat în timpul sezonului regulat 2015-2016, fiind analizate 2 echipe reprezentative pentru campionatele respective: Golden State Warriors şi CSM Oradea. În urma efectuării analizei, se obțin rezultate surprinzătoare care concluzionează anumite aspecte legate de eficiența în cadrul echipelor analizate.

\section{Introducere}

Fiind jocul sportiv care câștigă, în rândul tinerilor, un nivel crescut de popularitate, baschetul se caracterizează prin finețea, precizia și fantezia exercițiilor tehnice și tactice, prin talia înaltă și calitățile fizice deosebite ale sportivilor, toate acestea implicate într-o luptă sportivă care pretinde spirit de echipă și de sacrificiu.

Practicarea baschetului în România a devenit o metodă simplă și revigorantă de petrecere a timpului liber, copiii fiind văzuți din ce în ce mai des pe terenul de baschet. Din punct de vedere al marketingului, ultimii ani au însemnat și revirimentul mediatizării fenomenului baschetbalistic din România.

Liga Naţională de Baschet (LNB) propune jocuri interesante, echipele care activează în campionatul naţional reușind să creeze un spectacol sportiv inedit. Prin utilizarea tot mai frecventă a jucătorilor străini, se încearcă dinamizarea și profesionalizarea jocului, dorindu-se creșterea nivelului de performanță motrică, în vederea angrenării echipelor și în competițiile internaţionale.

În același timp, în ciuda diferențelor salariale uriașe, tot mai mulți jucători care au activat în NBA ajung să joace în Europa (Edelman, 2010).

National Basketball Association (NBA) reprezintă elita baschetului mondial. Cei mai bine cotați jucători se regăsesc în cele 30 de echipe împărțite pe 2 conferinte: Conferința de Est și Conferința de Vest. Cu abilități remarcabile, calități 
motrice desăvârșite, jocurile din NBA, creează spectacol pentru orice iubitor al sportului. Cu salarii incredibile (Lebron James, conform ESPN are în sezonul 2016-2017 salariul de 30,963,450 USD.), jucătorii de top au dus jocul de baschet spre o adevărată industire de marketing și management.

\section{Material și metode}

Ideea de la care s-a plecat în conceperea și analiza lucrării, este exprimată de ușurința cu care jucătorii profesioniști reușesc să concretizeze aruncările din acțiune, întreg procesul de reușită fiind pus în baza antrenamentului continuu și complex, dar și a particularităților jucătorilor. Utilizând o analiză cât mai exactă a rezultatelor obținute cu ajutorul metodei observației (Epuran, 2005), dorim evidențierea factorilor favorizanți pentru performanța sportivă.

Ipoteză. În acest studiu presupunem că există diferențe semnificative între procentul reușitelor aruncărilor din acțiune dintre o echipă din NBA și una care activează în LNB.

Având caracteristici diferite, prin prisma regulamentului de joc care nu este același, studiul poate fi obiectiv prin prisma analizei procentului de înscriere a coșurilor din cadrul jocurilor de baschet.

Echipele au fost analizate în perioada competițională 2015-2016, fiind urmărite evoluțiile acestora pe perioada întregului sezon.

Durata de joc reprezintă un prim aspect care necesită analizat. În LNB, conform regulamentului de joc (frbaschet.ro), un meci durează 40 de minute efective de joc. În NBA, timpul de joc este de 48 minute. Din acest motiv, ca și concepție de joc, profesioniștii din Liga Nord Americană folosesc un principiu de rulaj al jucătorilor, diferit față de România.

În medie jucătorii de bază sunt folosiți timp de $27.8( \pm 6.9)$ minute, iar rezervele timp de 11.3 ( \pm 7.0 ) minute de joc (Gonzalez et al. 2013). Modalitatea de finalizare a acțiunilor reprezintă o altă caracteristică diferită în jocul din NBA.

Datorită calităților motrice desăvârșite, jucătorii profesioniști folosesc "postup-ul" ca metodă frecventă de finalizare. În schimb, în Europa, de obicei, doar jucătorii centru primesc mingea în "post" cu scopul de a finaliza acțiunea (Mavridis, 2009).

Adevărați atleți, o altă metodă facilă de finalizare a acțiunilor o reprezintă contraatacul. Mărind intensitatea contraatacului, jucătorii din NBA reușesc să-și mărească procentajul de reușită și astfel să-și apropie victoriile din meciuri (Courel, McRobert \& Cardenas, 2014).

Dimensiunea terenului este diferită, atât din punct de vedere al dimensiunilor, dar, mai ales, prin prisma spațiului delimitat pentru aruncarea de 3 puncte (Fig.1).

Jucătorii din Europa aruncă pentru 3 puncte cu $0,5 \mathrm{~m}$. mai aproape decât cei din NBA, fiindu-le astfel, teoretic, mai ușor marcarea de puncte de la distanță. 


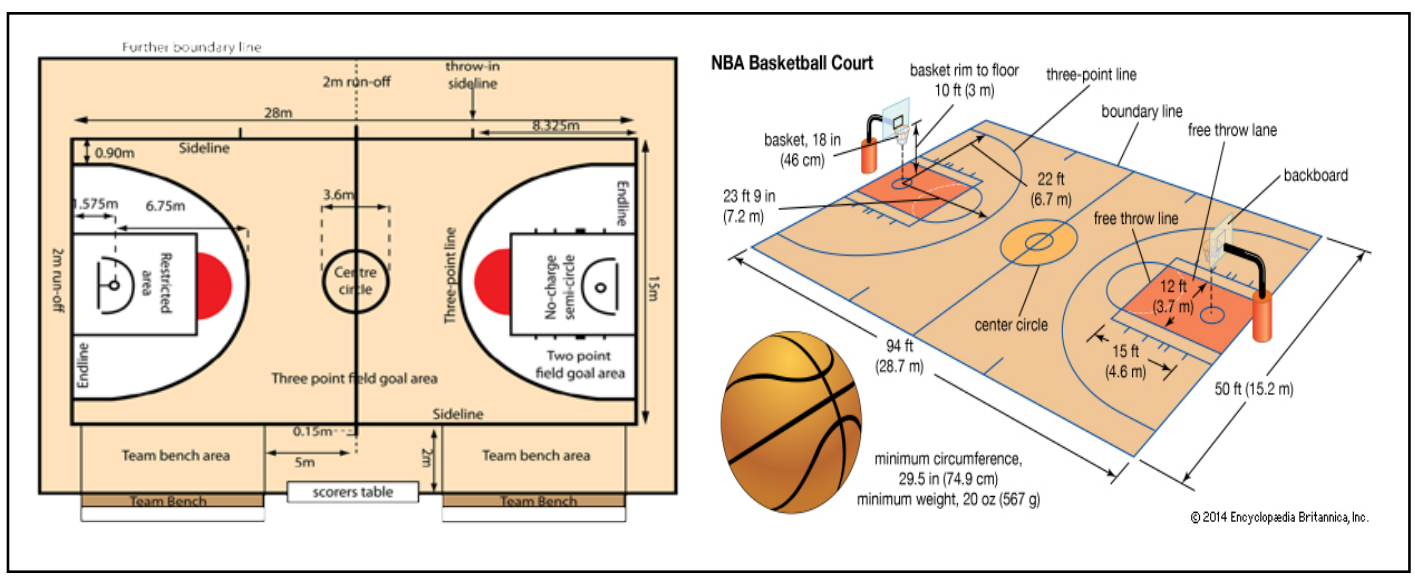

Figura 1. Dimensiunile standard ale terenurilor de baschet din LBA respectiv NBA (Tutorialpoint, Pinterest)

În cadrul lucrării au fost analizate reușitele din acțiune ale celor 2 echipe care au câștigat campionatele în sezonul 2015-2016 din NBA respectiv LNB. Aceste echipe sunt CSM Oradea și Golden State Warriors.

Echipa de peste Ocean are în componență următorii jucători (Tabel 1):

Tabel 1. Jucătorii echipei Golden State Warriors, sezonul 2015-2016 (Fox Sports Networks)

\begin{tabular}{lcc}
\hline Nume & Înălțime(cm) & Post \\
\hline Ezeli Festus & 211 & Pivot \\
Thompson Klay & 201 & Fundaş \\
Barnes Harrison & 203 & Extremă \\
Green Draymond & 201 & Extremă \\
Curry Stephen & 190 & Coordonator \\
Barbosa Leandro & 190 & Coordonator \\
Bogut Andrew & 213 & Pivot \\
Iguodala Andre & 198 & Extremă \\
Livingston Shaun & 201 & Fundaş \\
Rush Brandon & 198 & Fundaş \\
Speights Marreese & 208 & Extremă/Pivot \\
Clark Ian & 190 & Fundaş \\
Varejao Anderson & 211 & Pivot \\
McAdoo James-Michael & 206 & Extremă \\
\hline
\end{tabular}

În sezonul 2015-2016, echipa CSM Oradea i-a avut în componenţă pe următorii jucători (Tabelul 2): 
Tabel 2. Jucătorii echipei CSM Oradea, sezonul 2015-2016

(Federația Română de Baschet)

\begin{tabular}{lcc}
\hline Nume & Înălțime(cm) & Post \\
\hline Zeno Martin & 196 & Fundaș \\
Franklin William & 184 & Coordonator \\
Barnette Sean & 210 & Extremă \\
Nuhanovici Salih & 210 & Pivot \\
Mandache Andrei & 191 & Fundaș/Extremă \\
Lucic Uros & 207 & Extremă de forță \\
Markovic Radovan & 193 & Fundaș \\
Barac Nemanja & 194 & Fundaș \\
Zupan Miha & 205 & Extremă/Pivot \\
Lupusavei Silviu & 182 & Fundaș \\
Pașca Rareș & 198 & Extremă \\
Niculescu Bogdan & 199 & Extremă \\
Țibârnă Bogdan & 210 & Pivot \\
Petrișor Cătălin & 184 & Coordonator \\
\hline
\end{tabular}

Cele două echipe au disputat un număr diferit de jocuri împotriva adversarilor (Tabelul 3), în cadrul acestor meciuri fiecărui component al echipei i-a fost analizată prestația ofensivă, în vederea cuantificării rezultatelor.

Tabel 3. Evoluția echipelor aflate în cercetare pentru sezonul 2015-2016

\begin{tabular}{lccc}
\hline Echipa & Nr. total de meciuri & Victorii & Înfrângeri \\
\hline CSM Oradea & 32 & 23 & 9 \\
Golden State Warriors & 82 & 73 & 9 \\
\hline
\end{tabular}

\section{Rezultate și discuții}

În cadrul acestui studiu au fost comparate aruncările din acțiune pentru un număr total de 114 jocuri, rezultatele obținute fiind relevante pentru elaborarea concluziilor. Astfel, situația pentru echipa de baschet Golden State Warriors este prezentată în Tabelul 4.

Echipa campioană a României, CSM Oradea prezintă următoarele valori statistice pentru sezonul 2015-2016 în Tabelul 5. 
Tabel 4. Statistica pentru echipa Golden State Warriors, sezonul 2015-2016 (Sports Reference)

\begin{tabular}{lccccc}
\hline Nume jucător & Jocuri & Puncte/meci & Aruncări/meci & $\begin{array}{c}\text { Procentaj } \\
\text { 2 pct. }\end{array}$ & $\begin{array}{c}\text { Procentaj } \\
\text { 3. pct. }\end{array}$ \\
\hline Stephen Curry & 79 & 30.1 & 10.2 & $50.4 \%$ & $45.4 \%$ \\
Klay Thompson & 80 & 22.1 & 8.1 & $47 \%$ & $42.5 \%$ \\
Draymond Green & 81 & 14 & 5 & $49 \%$ & $38.8 \%$ \\
Harrison Barnes & 66 & 11.7 & 4.5 & $46.6 \%$ & $38.3 \%$ \\
Andre Iguodala & 65 & 7 & 2.7 & $47.8 \%$ & $35.1 \%$ \\
Marrese Speights & 72 & 7.1 & 2.7 & $43.2 \%$ & $38.7 \%$ \\
Festus Ezeli & 46 & 7 & 2.7 & $54.8 \%$ & $0.0 \%$ \\
Shaun Livingston & 78 & 6.3 & 2.6 & $53.6 \%$ & $16.7 \%$ \\
Leandro Barbosa & 68 & 6.4 & 2.5 & $46.2 \%$ & $35.5 \%$ \\
Andrew Bogut & 70 & 5.4 & 2.5 & $62.7 \%$ & $100.0 \%$ \\
Brandon Rush & 72 & 4.2 & 1.5 & $42.7 \%$ & $41.4 \%$ \\
Ian Clark & 66 & 3.6 & 1.3 & $44.1 \%$ & $35.7 \%$ \\
James Michael McAdoo & 41 & 2.9 & 1.1 & $53.6 \%$ & $50.0 \%$ \\
Andreson Varejao & 53 & 2.6 & 1 & $42.7 \%$ & $0.0 \%$ \\
\hline
\end{tabular}

Tabel 5. Statistica pentru echipa CSM Oradea, sezonul 2015-2016 (Federația Română de Baschet)

\begin{tabular}{llllll}
\hline Nume jucător & \multirow{2}{*}{ Jocuri } & Puncte/meci & Aruncări/meci & $\begin{array}{l}\text { Procentaj } \\
\text { 2 pct. }\end{array}$ & $\begin{array}{l}\text { Procentaj } \\
\text { 3. pct. }\end{array}$ \\
\hline Daniel Popescu & 13 & 2.2 & 0.5 & $33.3 \%$ & $42.1 \%$ \\
William Franklin & 22 & 9.5 & 4.3 & $48.9 \%$ & $36.4 \%$ \\
Bogdan Niculescu & 14 & 0.9 & 0.4 & $50.0 \%$ & $25.0 \%$ \\
Nemanja Barac & 17 & 7.4 & 4.4 & $56.0 \%$ & $15.0 \%$ \\
Miha Zupan & 8 & 10.5 & 3.6 & $55.0 \%$ & $43.8 \%$ \\
Catalin Petrisor & 7 & 0.7 & 0.6 & $25.0 \%$ & $0.0 \%$ \\
Radovan Markovic & 22 & 13.7 & 3.2 & $60.0 \%$ & $43.3 \%$ \\
Rares Pasca & 22 & 2.5 & 1 & $45.0 \%$ & $32.0 \%$ \\
Bogdan Tibarna & 10 & 7.5 & 3.7 & $64.9 \%$ & $40.0 \%$ \\
Salih Nuhalovic & 21 & 8.8 & 6.5 & $53.7 \%$ & $0.0 \%$ \\
Silviu Lupusavei & 1 & 0 & 0 & $0.0 \%$ & $0.0 \%$ \\
Sean Barnette & 21 & 12.9 & 8.2 & $49.7 \%$ & $43.6 \%$ \\
Uros Lucic & 21 & 10.3 & 6.4 & $47.4 \%$ & $41.8 \%$ \\
Andrei Mandache & 22 & 8.5 & 3.3 & $58.3 \%$ & $32.1 \%$ \\
\hline
\end{tabular}

Raportul dintre numărul de aruncări utilizate și înscrise de către jucătorii celor două echipe, sunt prezentate în Tabelul 6.

Tabel 6. Eficiența aruncărilor din acțiune pentru cele 2 echipe analizate

\begin{tabular}{ccc}
\hline Echipa & Procentaj 2 puncte & Procentaj 3 puncte \\
\hline Golden State Warriors & $48.7 \%$ & $41.6 \%$ \\
CSM Oradea & $52.8 \%$ & $37.6 \%$ \\
\hline
\end{tabular}




\section{Discuții}

Analizând rezultatele obținute, putem elabora anumite concluzii privind raportul dintre procentul reușitelor din acțiune pentru cele două echipe aflate în studiu. Dacă în cazul aruncărilor de 2 puncte, echipa CSM Oradea are un procentaj mai mare decât echipa din NBA, în cazul aruncărilor de 3 puncte, situația se inversează.

Explicațiile pot fi multiple, raportate la nivelul de joc existent din cele două campionate. Numărul mare de reușite de 3 puncte pentru echipa Golden State Warriors reprezintă noua filosofie de joc a NBA-ului. Echipele preferă aruncările de la distanță, stabilind noi recorduri de eficacitate (25 aruncări reușite din 39 încercări într-un joc de către Cleveland Cavaliers, în data 3.03.2017). Dacă echipa menționată a aruncat de 39 de ori la coș de 3 puncte, acest fapt reprezintă o medie de 10 aruncări/sfert, o valoare extrem de ridicată pentru jocul de baschet contemporan. Totuși, diferența dintre reușita aruncărilor de 2 puncte și cele de 3 puncte este relativ mică $(48,7 \%$ și $41.6 \%)$, această situație indicând pregătirea tehnică excepțională a jucătorilor profesioniști, care reușesc să atingă performanțe deosebite în contextul unor apărări agresive.

În LNB, cu toate că distanța de la care se contabilizează o aruncare de 3 puncte este cu $0,5 \mathrm{~m}$. mai mică decât în NBA, procentajul aruncărilor de la distanță, suferă un dezechilibru major față de cel de la semidistanță sau din apropierea panoului $(52,8 \%$ față de $37,6 \%)$. Se atestă astfel modalitatea de pregătire tactică a unui joc, în care combinațiile sunt realizate astfel încât jucătorii să beneficieze de aruncări necontestate din apropierea coșului. Această situație evidențiază caracteristicile jocului de baschet din România, în care tehnica din timpul jocului poate fi îmbunătățită.

\section{Concluzii}

Comparând rezultatele echipelor studiate, putem afirma că există diferențe semnificative între procentajul reușitelor din acțiune dintre Golden StateWarriors și CSM Oradea, confirmând ipoteza propusă.

Dacă echipa din România are, surprinzător, un procent mai mare de reușită decît cea din SUA la aruncările de 2 puncte, pentru aruncările de 3 puncte, americanii sunt net superiori. Situația se poate explica astfel: plecând de la dorința jucătorilor din NBA de a produce spectacol și ajungând la posibilitatea de a obține un punctaj mai mare decât un eventual adversar care ar utiliza preponderent aruncările de 2 puncte, jocul de peste Ocean capătă valențe deosebite.

Totodată, faptul că rezervele sunt utilizate mai mult timp, decât în Europa, face ca jucătorii titulari să fie mai odihniți astfel încât să nu-şi piardă din virtuozitatea tehnică.

Meciurile de baschet reușesc să aducă în săli un număr crescut de spectatori. $\mathrm{Cu}$ toate că are caracteristici diferite prin prisma jucătorilor care îl reprezintă, frumusețea și spectaculozitatea din timpul jocului trebuie admirată, fiind un punct de plecare în promovarea și încurajarea practicării, pe toate palierele de vârstă a jocului de baschet. 